\title{
DEFICIÊNCIA HÍDRICA AGRAVA OS SINTOMAS FISIOLÓGICOS DA CLOROSE VARIEGADA DOS CITROS EM LARANJEIRA 'NATAL' $\left({ }^{1}\right)$
}

\author{
EDUARDO CARUSO MACHADO $\left(2^{*}\right)$; RICARDO FERRAZ DE OLIVEIRA $\left({ }^{3}\right)$; \\ RAFAEL VASCONCELOS RIBEIRO $\left({ }^{2}\right)$; CAMILO LÁZARO MEDINA $\left({ }^{4}\right)$; \\ EDUARDO SANCHES STUCHI $\left({ }^{5}\right)$; LUIZ CARLOS PAVANI $\left({ }^{6}\right)$
}

\begin{abstract}
RESUMO
A clorose variegada dos citros (CVC) é uma doença que tem promovido sérios prejuízos aos laranjais das regiões Norte e Nordeste do Estado de São Paulo, onde a deficiência hídrica e as altas temperaturas são mais frequentes. Assim, este trabalho objetivou a avaliação do efeito da deficiência hídrica no desenvolvimento de sintomas fisiológicos em laranjeira 'Natal' com CVC. Foram realizadas medidas do potencial da água na folha, transpiração, condutância estomática e assimilação de $\mathrm{CO}_{2}$, em laranjeiras em condições naturais e submetidas à irrigação. O delineamento experimental foi em blocos ao acaso com cinco repetições. A condutância estomática, a transpiração diária e o potencial da água na folha foram menores nas plantas com CVC. A assimilação diária de $\mathrm{CO}_{2}$ foi menor nas laranjeiras com $\mathrm{CVC}$ mesmo quando irrigadas. De fato, a irrigação diminuiu o efeito da CVC, porém não impediu o estabelecimento da doença em laranjeiras inoculadas com Xylella fastidiosa. Em relação aos demais tratamentos, as plantas infectadas e mantidas sob condições naturais (sem irrigação) apresentaram maior comprometimento das trocas gasosas, mesmo quando as avaliações fisiológicas foram feitas em período úmido (verão).
\end{abstract}

Palavras-chaves: Citrus sinensis, relações hídricas, trocas gasosas, Xylella fastidiosa.

\section{ABSTRACT \\ WATER DEFICIENCY INTENSIFIES PHYSIOLOGICAL SYMPTOMS OF CITRUS VARIEGATED CLOROSIS IN ‘NATAL’ SWEET ORANGE PLANTS}

Citrus variegated chlorosis (CVC) is a disease that has caused serious economical losses in citrus grove located in the North and Northeastern regions of São Paulo State, where water deficiency and high temperature occur frequently. Therefore, the aim of this work was to evaluate the influence of water deficiency on the development of physiological symptoms in 'Natal' sweet orange plants with CVC. Measurements of leaf water potential, transpiration, stomatal conductance e $\mathrm{CO}_{2}$ assimilation were taken in plants under natural conditions and submitted to irrigation. The experimental design was in randomized blocks, with five replications. Stomatal conductance, daily transpiration and leaf water potential were lower in $\mathrm{CVC}$-affected plants. The daily $\mathrm{CO}_{2}$ assimilation was reduced in $\mathrm{CVC}$-affected plants, even in irrigated ones. In fact, irrigation decreased the negative effects of CVC, however, it did not prevent disease establishment in sweet orange plants inoculated with Xylella fastidiosa. Compared to other treatments, infected plants submitted to natural conditions (without irrigation) exhibited higher constrain of leaf gas exchange, even when measurements were taken during humid period (summer).

Key words: Citrus sinensis, gas exchange, water relations, Xylella fastidiosa.

( $\left.{ }^{1}\right)$ Recebido para publicação em 14 de setembro 2006 e aceito em 9 de março de 2007.

$\left({ }^{2}\right)$ Instituto Agronômico, Centro de Pesquisa e Desenvolvimento em Ecofisiologia e Biofísica, Caixa Postal 28, 13001-970 Campinas (SP). E-mail: caruso@iac.sp.gov.br $\left(^{*}\right)$ Autor correspondente; rafael@iac.sp.gov.br

$\left({ }^{3}\right)$ Escola Superior de Agricultura “Luiz de Queiroz", Departamento de Ciências Biológicas, Caixa Postal 9, 13418-900 Piracicaba (SP). E-mail: rfo@esalq.usp.br

$\left({ }^{4}\right)$ Conplant, Rua Francisco Andreo Aledo, 22, 13084-200 Barão Geraldo (SP). E-mail: clmedina@conplant.com.br

$\left({ }^{5}\right)$ Embrapa Mandioca e Fruticultura Tropical, Caixa Postal 7, 48380-000 Cruz das Almas (BA). E-mail: stuchi@estacaoexperimental.com.br

$\left({ }^{6}\right)$ Universidade Estadual Paulista, Faculdade de Ciências Agrárias e Veterinárias, Departamento de Engenharia Rural, Via de acesso Prof. Paulo Donato Castellane, s/n, 14884-900 Jaboticabal (SP). E-mail: lcpavani@fcav.unesp.br 


\section{INTRODUÇÃO}

A clorose variegada dos citros (CVC) é uma das principais doenças que afetam laranjeiras doces no Brasil. O agente causal desta doença é a Xylella fastidiosa (X.f.) bactéria limitada ao xilema. Essa bactéria, ao colonizar o xilema das plantas, causa entupimento dos vasos condutores, o que diminui a condutância hidráulica do caule e o fluxo de seiva (McElrone et al., 2003; Machado et Al., 2006). Os sintomas de deficiência hídrica em plantas infectadas pela X.f. são devidos à colonização e ao entupimento do xilema pelas próprias bactérias e/ou pela deposição de gomas e tiloses. Certamente, a severidade da doença está relacionada com o grau de colonização do xilema (Hopkins, 1989; Purcell \& Hopkins, 1996; Alves et al., 2004). Assim, em plantas com CVC observam-se abscisão de folhas, necrose marginal, crescimento atrasado na primavera, sintomas de deficiência hídrica e declínio geral do vigor (Purcell e Hopkins, 1996).

Em laranjeiras, o potencial de água de folha, a assimilação de $\mathrm{CO}_{2}$, a transpiração e a condutância estomática são menores em plantas com CVC (MACHADO et al., 1994, Medina, 2002; Habermann et al., 2003; Ribeiro et al., 2003a,b; 2004). A diminuição da fotossíntese em laranjeira com CVC pode estar relacionada com a diminuição na condutividade hidráulica do xilema e conseqüente fechamento estomático. Esses sintomas são atribuídos ao bloqueio dos vasos do xilema devido à colonização pelas bactérias (MACHADO et al., 1994). Alves et al. (2004) observaram que a intensidade dos sintomas está relacionada com o bloqueio dos vasos do xilema, os quais podem causar reduções de até $50 \%$ no fluxo de seiva (MACHADO et al., 2006). Além dos efeitos difusivos, alguns autores sugerem que a limitação da fotossíntese em plantas infectadas pela X.f. também é devida a injúrias nas reações bioquímicas (HABERMANN et al., 2003; RibEIRO et al., 2003a,b; 2004; MACHADO et al., 2006).

Os últimos levantamentos da disseminação da CVC no Estado de São Paulo revelaram que a proporção de plantas infectadas aumentou de $22 \%$ em 1996 para 43\% em 2005 (Fundecitrus, 2005). O estabelecimento e desenvolvimento de CVC são afetados por fatores ambientais, resultando em maior incidência nas regiões Norte (69\%), Noroeste (56\%) e Central (51\%) do Estado de São Paulo, quando comparadas às regiões Sul $(4,7 \%)$ e Oeste $(9,5 \%)$. De fato, nas regiões Sul e Oeste as temperaturas médias são menores e também há menor ocorrência de déficits hídricos, enquanto nas regiões Central, Noroeste e Norte as temperaturas são mais elevadas e a deficiência hídrica mais freqüente e com maior duração (Ribeiro et al., 2006).
A patogenicidade de X.f. é agravada com a ocorrência de estresses ambientais (Hopkins, 1989), sendo o desenvolvimento da doença favorecido pela deficiência hídrica, outras doenças, danos no sistema radicular e superprodução de frutos (HopKINs, 1989; Purcell e Hopkins, 1996; Medina, 2002; McElrone e Forseth, 2001). McElrone e Forseth (2001) e Medina (2002) observaram que os sintomas e os efeitos negativos da X.f. em plantas envasadas são agravados pela ocorrência de deficiência hídrica. Em parreiras, os sintomas do mal de Pierce, também causado por X.f., são agravados por estresses adicionais (HopKINS, 1989).

Visto que a CVC é mais severa nas regiões Norte e Noroeste do Estado de São Paulo, onde são mais freqüentes a ocorrência de deficiência hídrica e altas temperaturas, é desejável que se desenvolvam pesquisas que analisem como as condições ambientais afetam as respostas fisiológicas de plantas infectadas em condição de campo. Embora os mecanismos fisiológicos e bioquímicos que caracterizam o estabelecimento da doença não sejam bem compreendidos em condições de estresse, estudos têm mostrado que a redução no potencial de água de folha pode afetar o crescimento da planta sem afetar o desenvolvimento do patógeno (BOYER, 1995).

O objetivo desta pesquisa foi avaliar a influência da deficiência hídrica na ocorrência de sintomas fisiológicos em laranjeira ' $\mathrm{Natal}^{\prime}$ causados pela CVC, considerando-se medidas de trocas gasosas e potencial de água na folha em plantas sadias e doentes cultivadas sob condições naturais ou sob irrigação.

\section{MATERIAL E MÉTODOS}

O experimento foi instalado na Estação Experimental de Citricultura de Bebedouro (EECB), no município de Bebedouro (20 $56^{\prime} 58^{\prime \prime} \mathrm{S} ; 48^{\circ} 28^{\prime} 0^{\prime \prime} \mathrm{O}$; altitude de $601 \mathrm{~m}$ ), Estado de São Paulo, em área de Latossolo Vermelho Distrófico típico textura argilosa a moderado hipoférrico. O delineamento experimental utilizado foi o de blocos casualizados com quatro tratamentos e cinco repetições: laranjeiras sadias com (Sadia-100) ou sem (Sadia-0) reposição por irrigação de $100 \%$ da água evapotranspirada e laranjeiras doentes com (CVC-100) ou sem (CVC-0) reposição da água evapotranspirada.

O ensaio foi implantado em 19 de fevereiro de 1999 com mudas sadias de laranjeira da variedade 'Natal' enxertadas em limoeiro 'Cravo'. O espaçamento de plantio foi de $6,0 \mathrm{~m}$ entre linhas e 4,0 m entre plantas na linha. Cada parcela era 
composta de 24 plantas distribuídas em 3 linhas de 8 plantas cada uma. A linha central de cada parcela foi reservada para as amostragens necessárias. A partir do plantio, foram feitas aplicações, em intervalos de aproximadamente 90 dias, de produtos sistêmicos via solo (aldicarb) e via tronco (imidacloprid) para impedir a presença de cigarrinhas e evitar a disseminação da Xylella fastidiosa (X.f.).

Nove meses após o plantio (novembro de 1999), metade das plantas foi submetida à inoculação com X.f. pelo método descrito por NunEs et al. (2004). Esse método consistiu em enxertar, por meio de encostia, mudas inoculantes acondicionadas em tubetes de $120 \mathrm{~mL}$. A planta inoculante foi enxertada no tronco principal das laranjeiras e lá permaneceu por seis meses. Para constatação da presença da bactéria na planta inoculada, utilizou-se o exame de reação de polimerase em cadeia (PCR) específica para X.f. estabelecido por Pooler e Hartung (1995).

As plantas foram irrigadas utilizando-se um microaspersor autocompensado por planta, com vazão de $42 \mathrm{~L} \mathrm{~h}^{-1}$ e ângulo de molhamento de $300^{\circ}$. A irrigação foi realizada duas vezes por semana, sendo o volume de água fornecido por planta resultante do balanço entre a lâmina d'água correspondente ao total de chuva efetiva ocorrida no intervalo (chuva que não excedia a capacidade de água disponível do solo $1,1 \mathrm{~mm} / \mathrm{cm}$ até a profundidade de $0,60 \mathrm{~m}$ ) entre as duas irrigações e a lâmina d'água relativa à evapotranspiração total da cultura, sendo calculada por meio do produto da evapotranspiração de referência (ETo) estimada diariamente segundo o modelo de Penman-MonteithFAO pelo coeficente de cultura $(\mathrm{Kc})$ para citros (ALLEN et al., 1998). Os balanços hídricos foram feitos utilizando-se a planilha eletrônica desenvolvida por Rolim et al. (1998).

As variáveis ambientais [temperatura do ar, saldo de radiação solar, fluxo de calor no solo, velocidade do vento, umidade relativa e déficit de pressão de vapor do ar (DPV)] foram monitoradas por meio de uma miniestação climatológica automática, localizada a $0,5 \mathrm{~km}$ do pomar.

Em 15 de agosto e 11 de outubro de 2000 e em 25 de julho e 19 de dezembro de 2002, foram feitas medidas da assimilação de $\mathrm{CO}_{2}$ (A), transpiração (E), condutância estomática (gs), temperatura foliar e densidade de fluxo de fótons fotossinteticamente ativos (DFFFA) com um sistema portátil de medidas de fotossíntese (LI-6400, Licor Inc. Lincoln NE, EUA). Essas variáveis foram medidas entre 7 e $17 \mathrm{~h}$, em intervalos de aproximadamente 1 hora. Com base nas medidas instantâneas de assimilação de $\mathrm{CO}_{2}$ e transpiração foram calculados os valores diários integrados: assimilação diária de $\mathrm{CO}_{2}\left(\mathrm{Ai}, \mathrm{mmol} \mathrm{m} \mathrm{m}^{-2} \mathrm{~d}^{-1}\right)$ e transpiração diária $\left(E i, m o l \mathrm{~m}^{-2} \mathrm{~d}^{-1}\right)$. A partir desses valores integrados calculou-se a eficiência diária do uso da água [EUA=Ai/Ei, $\mathrm{mmol} \mathrm{CO}_{2}$ $\left.\left(\mathrm{mol} \mathrm{H}_{2} \mathrm{O}\right)^{-1}\right]$. Em todas as épocas de medidas, utilizaram-se folhas completamente expandidas com idade entre 6 e 8 meses, com pouco ou nenhum sintoma de clorose, expostas ao Sol durante todo o período de medidas. Detalhes do método são descritos em Machado et al. (1994).

O potencial da água na folha $\left(\Psi_{1}\right)$ foi medido com uma câmara de pressão, segundo método descrito por KaUfMAnN (1968). Mediu-se $\Psi_{1}$ às 6 h (pré-manhã) e às $14 \mathrm{~h}$, com quatro repetições por tratamento. As folhas avaliadas estavam localizadas próximas às das medidas das trocas gasosas.

Os resultados foram submetidos à análise de variância e as médias comparadas pelo teste de Tukey a $5 \%$ de probabilidade.

\section{RESULTADOS E DISCUSSÃO}

Na figura 1, verificam-se as variações das temperaturas máxima e mínima, precipitação pluvial e quantidade de água armazenada no solo nos dois anos (2000 e 2002) em que foram efetuadas as medidas de trocas gasosas e potencial de água na folha. Em 2000, entre abril e novembro houve deficiência hídrica, dada pelo armazenamento negativo, enquanto entre janeiro e abril ocorreu excedente hídrico. Em 2002, o déficit hídrico no solo ocorreu entre abril e outubro e em meado de agosto houve precipitações pluviais significativas e o déficit hídrico diminuiu até ser praticamente nulo a partir do último decêndio de novembro. Em dezembro de 2002, quando não ocorreu déficit hídrico no solo (Figura 1), os valores de $\Psi_{1}$ foram semelhantes nos tratamentos Sadia-0 e Sadia-100, e as plantas com deficiência hídrica recuperaram-se totalmente (Figura 2).

Dez meses após a inoculação (agosto de 2000), os valores de $\Psi_{1}$ da pré-manhã nas laranjeiras CVC-100 e CVC-0 foram semelhantes aos das plantas Sadia-100 e Sadia-0 respectivamente (Figura 2). Às $14 \mathrm{~h}$, quando a temperatura do ar e DPV são mais elevados (Figura 3), o $\Psi_{1}$ das plantas CVC-0 foi menor $(\mathrm{p}<0,05)$ em relação às Sadia-0, Sadia-100 e CVC-100 (Figura 2), pois já estava ocorrendo efeito da X.f. nessas plantas, mesmo que ainda pouco intenso e somente nas horas de maior demanda atmosférica. 


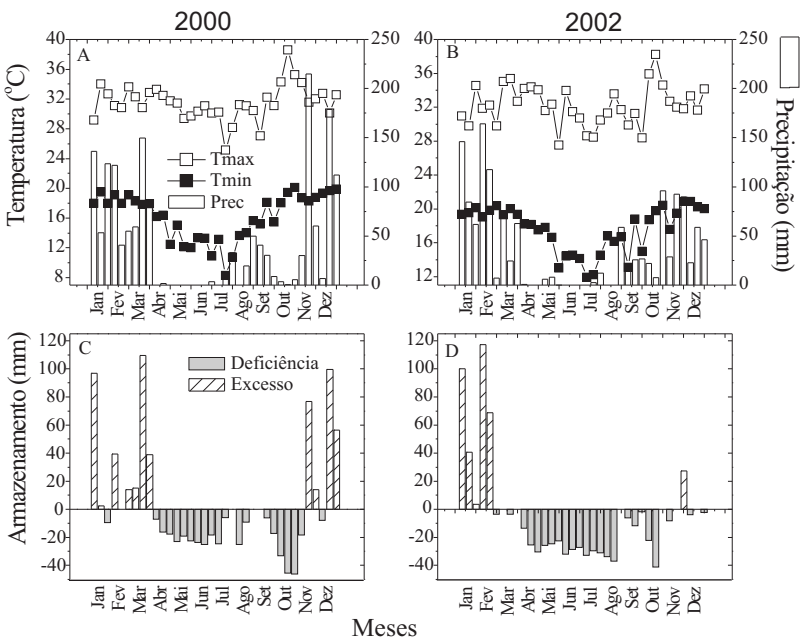

Figura 1. (A,B) Variação anual da temperatura média máxima $(\square)$ e mínima $(\square)$; precipitação pluvial, e (C,D) deficiência e excesso de água no solo a cada decêndio em 2000 (A,C) e 2002 (B,D) em Bebedouro (SP).

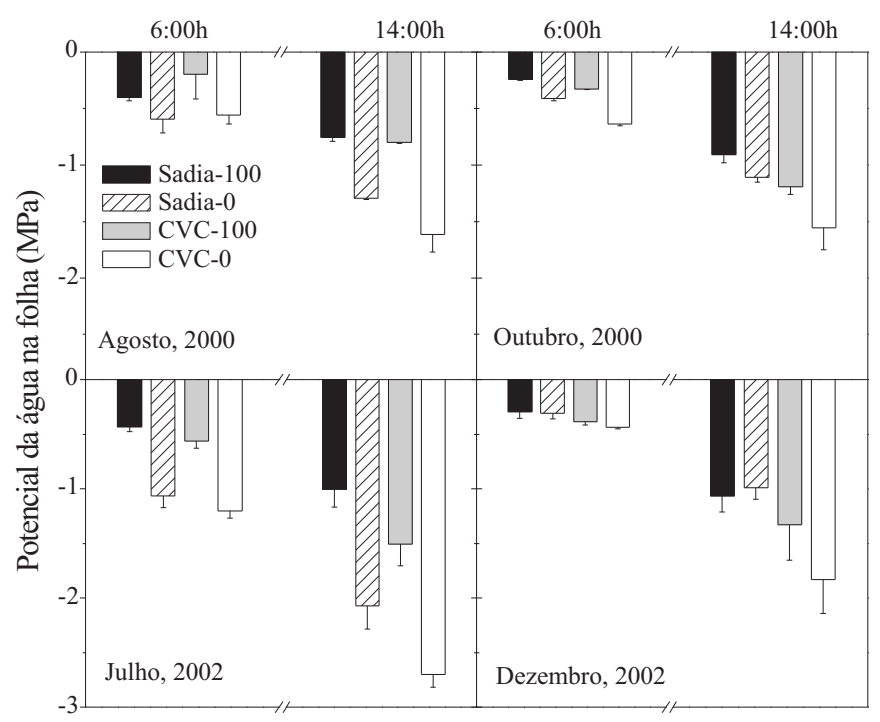

Figura 2. Potencial da água na folha (pré-manhã, $6 \mathrm{~h}$ e $14 \mathrm{~h}$ ) em laranjeiras 'Natal' sadias com (Sadia-100) e sem irrigação (Sadia-0) ou com clorose variegada dos citros com (CVC-100) e sem irrigação (CVC-0) em agosto e outubro de 2000, julho e dezembro de 2002, em Bebedouro (SP). Barras e linhas representam respectivamente o valor médio de quatro repetições e o desvio-padrão da média.

$\mathrm{O} \Psi_{1}$ das plantas doentes em outubro de 2000, julho e dzembro de 2002 foram menores $(p<0,05)$, tanto nas medidas de pré-manhã como das $14 \mathrm{~h}$, quano comparadas às plantas sadias (Figura 2). Essas diferenças foram progressivamente maiores com o passar do tempo e mais acentuadas nas medidas das 14 h (Figura 2), em função da maior demanda atmosférica (Figura 3). Em agosto e outubro de 2000 e julho de 2002, observaram-se nas laranjeiras Sadia-
0 , menores valores de $\Psi_{1}$, tanto na pré-manhã como às $14 \mathrm{~h}$, em relação às laranjeiras Sadia-100 (Figura 2), demonstrando o efeito do déficit hídrico no solo sobre essa variável. A queda acentuada dos valores de $\Psi_{1}$ entre a pré-manhã e a tarde, indica um desbalanço entre a água absorvida pelo sistema radicular e a transpirada pelas folhas, causando uma queda no conteúdo relativo de água na folha. Tal situação também acarreta em fechamento parcial dos estômatos, indicado pela redução da condutância estomática (Figura 4). A menor gs à tarde em relação à parte da manhã implica, por sua vez, menor transpiração e assimilação de $\mathrm{CO}_{2}$ (Figura 5)

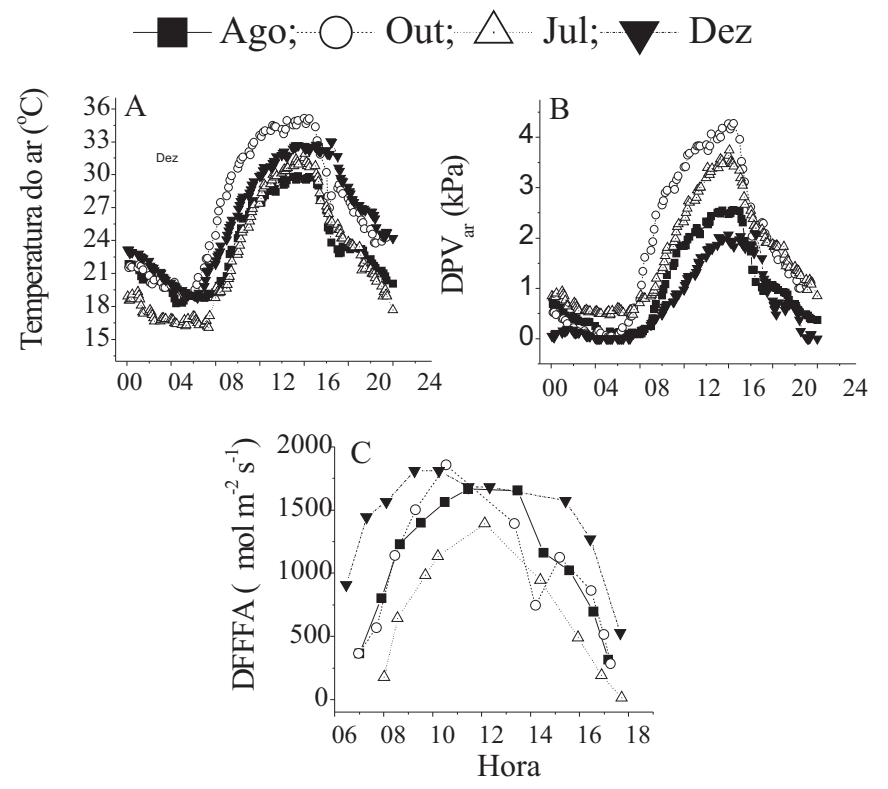

Figura 3. Variação diária da temperatura do ar (A), do déficit de pressão de vapor do ar (DPV, B) e da densidade de fluxo de fótons fotossinteticamente ativos (DFFFA, C) nos dias de medidas de trocas gasosas e de potencial da água na folha em laranjeiras 'Natal' com e sem clorose variegada dos citros, em Bebedouro (SP).

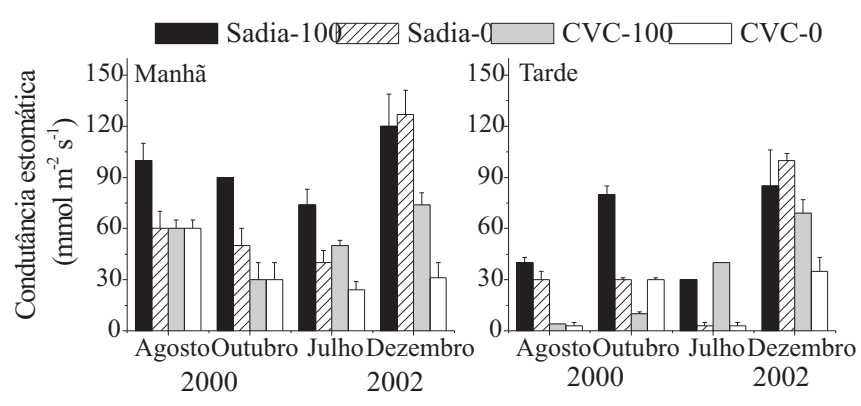

Figura 4. Condutância estomática às 9 h (Manhã) e às 14 h (Tarde) em laranjeiras 'Natal' sadias com (Sadia-100) e sem irrigação (Sadia-0) ou com clorose variegada dos citros com (CVC-100) e sem irrigação (CVC-0) em agosto e outubro de 2000, julho e dezembro de 2002, em Bebedouro (SP). Barras e linhas representam, respectivamente, o valor médio de cinco repetições e o desvio- padrão da média. 

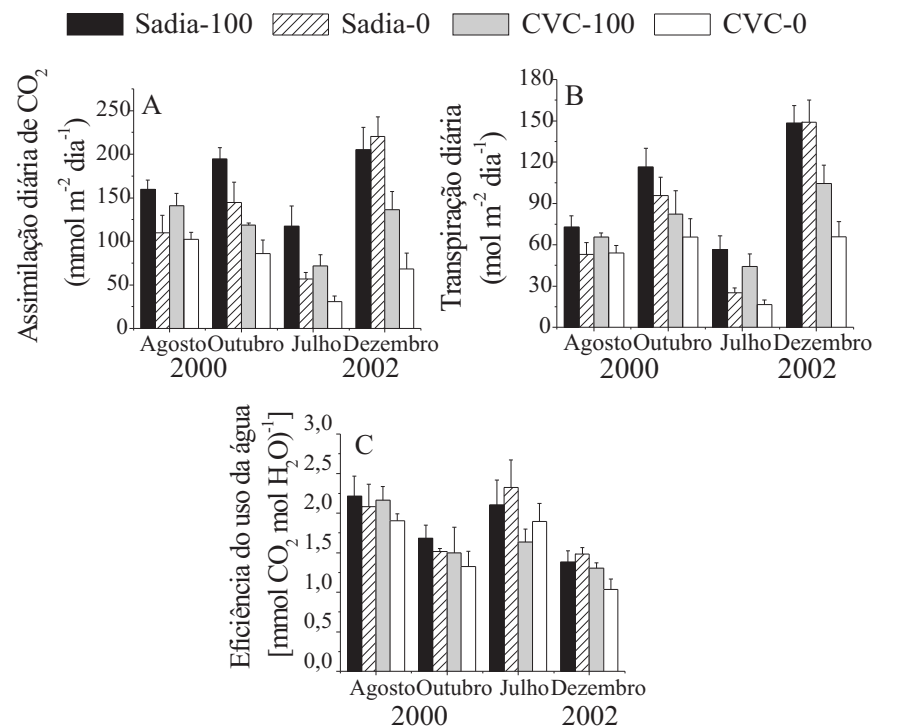

Figura 5. Assimilação diária de $\mathrm{CO}_{2}(\mathrm{~A})$, transpiração diária (B) e eficiência diária do uso da água (C) em laranjeiras 'Natal' sadias com (Sadia-100) e sem irrigação (Sadia-0) e com clorose variegada dos citros com (CVC-100) ou sem irrigação (CVC-0) em agosto e outubro de 2000, julho e dezembro de 2002, em Bebedouro (SP). Barras e linhas representam respectivamente o valor médio de cinco repetições e o desvio-padrão da média.

Em laranjeiras sadias, observou-se em Sadia100 maior gs $(p<0,05)$ que em Sadia-0 em agosto de 2000, outubro de 2000 e julho de 2002, em decorrência do déficit hídrico no solo (Figuras 1, 4). Em dezembro, gs foi semelhante nas plantas Sadia-100 e Sadia-0, visto que não houve deficiência hídrica nesse período. Em relação às plantas CVC-100, nas laranjeiras Sadia100 observou-se a maior gs $(p<0,05)$ em todos meses e nos dois horários de medidas (Figura 4), exceto em julho de 2002 à tarde. Portanto, a redução de gs em CVC-100 está relacionada à presença de X.f. (PCR positivo). A transpiração de Sadia-100 foi maior $(\mathrm{p}<0,05)$ em agosto, outubro e julho quando comparadas à CVC-100.

Esses resultados corroboram com aqueles observados por outros autores (MCELRONE e FORSETH, 2001, 2004; McElrone et al., 2003; Habermann et al., 2003; MACHADO et al., 1994, 2006) em plantas infectadas por X.f. Em laranjeiras 'Natal' infectadas pela X. $f$. foram observados decréscimos de até $50 \%$ no fluxo de seiva (MACHADO et al., 2006), em decorrência do entupimento parcial dos vasos do xilema. A queda do $\Psi_{1}$ das plantas com CVC está relacionada com a colonização do xilema pela X.f., o que aumenta significativamente a resistência à passagem de água e prejudica a reposição da água perdida pela transpiração. Alves et al. (2004) observaram em laranjeiras com sintomas médios e severos de CVC entre $8 \%$ e $11 \%$ dos vasos do xilema bloqueados. Plantas CVC-100, i.e. sem deficiência de água no solo, havia sintomas de deficiência hídrica semelhantes às plantas Sadia-0. Em vista da obstrução dos vasos do xilema, há maior dificuldade de reposição da água transpirada, tornando a folha menos túrgida e ocorrendo um fechamento parcial dos estômatos, dado pelo menor gs, e conseqüente redução da transpiração (Figuras 4 e 5B).

É importante observar que em dezembro de 2002 não houve déficit hídrico no solo (Figura 1), tanto que o $\Psi_{1}$ das plantas sadias foi semelhante. Esse processo revela que as plantas Sadia-0 recuperaramse totalmente após o restabelecimento da umidade no solo. Porém, as laranjeiras CVC-100 estavam com menores $\Psi_{1}(\mathrm{p}<0,05)$ em dezembro, tanto nas medidas de pré-manhã como às 14:00h, em relação às plantas Sadia-100 e Sadia-0, evidenciando que a irrigação não impediu os efeitos negativos da doença. As laranjeiras CVC-0, submetidas a déficits hídricos durante seu desenvolvimento, estavam com $\Psi_{1}$ significativamente menor em relação às CVC-100, mesmo em dezembro quando não ocorreu déficit hídrico. Esses resultados sugerem que a irrigação não impediu a influência da CVC nas trocas gasosas de laranjeiras, porém o déficit hídrico no solo proporcionou agravamento dos sintomas fisiológicos.

Na figura 5A, observa-se que a assimilação diária de $\mathrm{CO}_{2}$ variou entre os meses de medida. As maiores assimilações de $\mathrm{CO}_{2}$ ocorreram em dezembro (verão) e outubro (primavera), enquanto os menores valores, em julho e agosto (inverno). Mesmo nos tratamentos irrigados, os menores valores de Ai foram observados no inverno, evidenciando que as condições de temperatura mais elevada favoreceram a fotossíntese e o crescimento das plantas no verão e na primavera (MACHADO et al., 2002; RIBEIRO, 2006). Nos tratamentos não irrigados, em que ocorreu déficit hídrico em julho, agosto e outubro, houve redução acentuada de Ai $(p<0,05)$, tanto em plantas sadias como em doentes. No inverno, as plantas estavam com menor Ai em julho do que em agosto (Figura 5), o que pode estar relacionado com a menor quantidade de energia, o maior DPV e menor temperatura noturna em julho (Figura 3). Sabe-se que a fotossíntese de laranjeiras decresce significativamente com o aumento do DPV de 1,5 para 3,5 kPa (MACHADO et al., 2005) e que a atividade fotossintética é influenciada pela baixa temperatura noturna, como relatado em mangueiras (FLEXAs et al., 1999). A condutância estomática afeta a resposta sazonal da fotossíntese (FARIA et al., 1998; FleXAS et al., 2001; RibeIro, 2006) e é prejudicada pela temperatura do ar e disponibilidade de água (MACHADO et al., 2005; FLEXAS et al., 2001; RiBEIRO, 2006). 
Independentemente do mês de medida, a assimilação de $\mathrm{CO}_{2}$ nas plantas com $\mathrm{CVC}$ foi menor $(\mathrm{p}<0,05)$ que nas sadias. A assimilação diária de $\mathrm{CO}_{2}$ sempre foi maior nas plantas com CVC-100 em relação às CVC-0 (Figura 5A). Essas diferenças foram ocasionadas pelo déficit hídrico do solo, que ocorreu em agosto e outubro (2000) e julho (2002), como observado na figura 1. Assim, a redução na assimilação de $\mathrm{CO}_{2}$ foi devida ao efeito cumulativo da X.f. e da falta de água nos meses em que houve déficit hídrico.

Em dezembro, quando não houve déficit hídrico no solo, Ai das plantas Sadia-100 e Sadia-0 foi estatisticamente igual (Figura 5A). As plantas CVC100 mantiveram um valor de assimilação diária bem menor $(p<0,05)$, demonstrando que X.f. afetou significativamente esse processo. No entanto, Ai das plantas CVC-0 foi menor ainda $(p<0,05)$ que nas plantas CVC-100, demonstrando, à semelhança do que ocorreu em gs e Ei, que a deficiência hídrica causou um agravamento dos efeitos deletérios da doença sobre a planta.

A transpiração e a assimilação de $\mathrm{CO}_{2}$, como processos difusivos, foram afetados pelo fechamento parcial dos estômatos (Figuras 4 e 5). A relação entre $\mathrm{Ai} /$ Ei define a eficiência diária do uso de água (EUA). Comparativamente, a EUA das plantas com CVC foi menor do que as plantas sadias $(p<0,05)$ em julho $(p<0,05)$. Em dezembro, somente CVC-0 foi menos eficiente em relação aos outros tratamentos $(p<0,05)$. Em agosto e outubro as eficiências foram semelhantes $(p>0,05)$. O menor valor de EUA revela que para uma situação semelhante (clima) as plantas com CVC foram de menos assimilação de $\mathrm{CO}_{2}$ por unidade de água transpirada, podendo ser conseqüência de limitações impostas pela CVC na atividade bioquímica da fotossíntese (Habermann et al., 2003; Ribeiro et al., 2003a; 2004). Plantas com CVC tiveram decréscimos de gs, $\mathrm{Ei}$ e Ai, porém a queda relativa de Ai foi maior que de Ei causando redução de EUA. MEdina et al. (1999) observaram uma relação linear entre gs e transpiração e uma relação curvilínea entre gs e assimilação de $\mathrm{CO}_{2}$. Em julho, a EUA em plantas CVC100 e CVC-0 foram semelhantes ( $p>0,05)$, enquanto em dezembro a EUA foi menor $(p<0,05)$ no tratamento CVC-0 quando comparado a CVC-100 (Figura 5), apesar da não-ocorrência de déficit hídrico no solo. A transpiração e a assimilação de $\mathrm{CO}_{2}$ foram afetadas pelo fechamento parcial dos estômatos, mas a queda relativamente maior de Ai é um indicativo de que processos metabólicos da fotossíntese foram afetados. De fato, Ribeiro et al. (2003a, 2004) e Habermann et al. (2003) relatam menor eficiência de carboxilação em laranjeiras infectadas por X.f.
BOYer (1995) propõe que o estresse hídrico favorece o desenvolvimento do patógeno nas plantas por dois mecanismos principais: (a) redução da produção fotossintética induzida pela deficiência hídrica diminui a habilidade da planta em defenderse contra o patógeno; e/ou (b) o crescimento da planta é diminuído sem redução da habilidade do patógeno se desenvolver e reproduzir, agravando a doença. A X.f. provoca oclusão do xilema (HopKINS 1995; Alves et al., 2004) causando deficiência hídrica na folha e reduções em gs e $\Psi_{1}$. Conseqüentemente, o fechamento parcial dos estômatos causa menor difusão de $\mathrm{CO}_{2}$ para o cloroplasto, diminuindo a fixação de $\mathrm{CO}_{2}$. Inicialmente, a fotossíntese fica limitada por processos difusivos, porém com o agravamento da doença os processos bioquímicos também podem ser afetados.

\section{CONCLUSÕES}

1. A assimilação diária de $\mathrm{CO}_{2}$ e a transpiração diária de laranjeira 'Natal' são reduzidas em plantas com CVC.

2. A eficiência diária do uso de água é menor em laranjeiras com CVC, revelando que, além dos difusivos, outros processos fotossintéticos são afetados.

3. A ocorrência de déficit hídrico no solo agrava os efeitos negativos da CVC nas trocas gasosas.

4. A irrigação não impede a ocorrência dos sintomas fisiológicos de CVC em laranjeiras, apesar do efeito da X.f. ser menos severo em plantas irrigadas.

\section{AGRADECIMENTOS}

À Fapesp pelo apoio financeiro e concessão de bolsa a Rafael V. Ribeiro e ao CNPq pela concessão de bolsas a Eduardo C. Machado e Eduardo S. Stuchi. Aos diretores e funcionários da Estação Experimental de Citricultura de Bebedouro.

\section{REFERÊNCIAS}

ALLEN, R.G.; PEREIRA, L.S.; RAES, D.; SMITH, M. Crop evapotranspiration: guidelines for computing crop water requirements. Roma: FAO, 1998. 300p. (FAO, Irrigation and Drainage Paper 56)

ALVES, E.; MARUCCI, C.R.; LOPES, R.E.: LEITE, B. Leaf symptoms on plum, coffee and citrus and the relationship with the extent of xylem vessels colonized by Xylella fastidiosa. Journal of Phytopathology, London, v. 152, p.291-297, 2004. 
BOYER, J.S. Biochemical and biophysical aspects of water deficits and the predisposition to disease. Annual Review of Phytopathology, Boca Raton, v.33, p.151-274, 1995.

FARIA, T.; SILVÉRIO, D.; BREIA, E.; CABRAL, R.; ABADIA, A.; ABADIA, J.; PEREIRA, J.S.; CHAVES, M.M. Differences in response of carbon assimilation to summer stress (water deficits, high light and temperature) in four mediterranean tree species. Physiologia Plantarum, Copenhagen, v.102, p.419$428,1998$.

FLEXAS, J.; BADGER, M.; CHOW, W.S.; MEDRANO, H.; OSMOND, C.B. Analysis of the relative increase in photosynthetic $\mathrm{O}_{2}$ uptake when photosynthesis in grapevine leaves is inhibited following low night temperatures and/or water stress. Plant Physiology, Rockville, v.121, p.675-684, 1999.

FLEXAS, J.; GULIAS, J.; JONASSON, S.; MEDRANO, H.; MUS, $M$. Seasonal patterns and control of gas exchange in local populations of the Mediterranean evergreen shrub Pistacia lentiscus L. Acta Oecologica, Paris, v.22, p.33-43, 2001.

FUNDECITRUS. Estatísticas CVC. Disponível em: http:/// www.fundecitrus.com.br/escvcbr.htm. Acesso em 13 de julho de 2006.

HABERMANN, G.; MACHADO, E.C.; RODRIGUES, J.D.; MEDINA, C.L. $\mathrm{CO}_{2}$ assimilation, photosynthetic light response curves, and water relations of 'Pêra' sweet orange plants infected with Xylella fastidiosa. Brazilian Journal of Plant Physiology, Londrina, v.15, p.79-87, 2003.

HOPKINS, D.L. Xylella fastidiosa: xylem-limited bacterial pathogen of plants. Phytopathology, v.27, p.271-290, 1989.

KAUFMANN, M. Evaluation of the pressure chamber method for measurement of water stress in citrus. Proceedings of the American Society for Horticultural Science, v.93, p.186-198, 1968.

MACHADO, E.C.; MEDINA, C.L.; GOMES, M.M.A.; HABERMANN G. Variação sazonal da taxa de fotossíntese, condutância estomática e potencial da água na folha em laranjeira 'Valência'. Scientia Agricola, Piracicaba, v.59, p.53-58, 2002.

MACHADO, E.C.; OLIVEIRA, R.F.; RIBEIRO, R.V.; MEDINA, C.L.; STUCHI, E.S.; MARIN, F.R.; SILVA, J.A.B.; SILVA, S.R. Fluxo de seiva e fotossíntese em laranjeira 'Natal' com clorose variegada dos citros. Pesquisa Agropecuária Brasileira, Brasília, v. 41, p. 911-918, 2006.

MACHADO, E.C.; QUAGGIO, J.A.; LAGÔA, A.M.M.A.; TICELLI, M.; FURLANI, P.R. Trocas gasosas e relações hídricas em citros com clorose variegada dos citros. Revista Brasileira de Fisiologia Vegetal, Londrina, v.6, p.53-57, 1994.

MACHADO, E. C.; SCHMIDT, P. T.; MEDINA, C.L. ; RIBEIRO, R. V. Respostas da fotossíntese a fatores ambientais em três espécies de citros. Pesquisa Agropecuária Brasileira, Brasília, v. 40, p.1161-1170, 2005.

McELRONE, A.J.; FORSETH, I.N. Effects of water stress on synptomatology and growth of Parthenocisssus quinquefolia infected by Xylella fastidiosa. Plant Disease, St. Paul, v.85, p.1160$1164,2001$.
McELRONE, A.J.; FORSETH, I.N. Photosynthetic response of a temperate liana to Xylella fastidiosa infection and water stress. Journal of Phytopathology, Berlin, v.152, p.9-20, 2004.

McELRONE, A.J.; SHERALD, J.L.; FORSETH, I.N. Interactive effects of water stress and xylem-limited bacterial infection on water relations of a host vine. Journal of Experimental Botany, Oxford, v.54, p.419-430, 2003.

MEDINA, C.L. Fotossíntese, relações hídricas e alterações bioquímicas em laranjeira 'Pêra' com CVC e submetida à deficiência hídrica. 2002. 147 p. Tese (Doutorado) - Instituto de Biologia, Universidade Estadual de Campinas, Campinas, 2002.

MEDINA, C.L.; MACHADO, E.C.; GOMES, M.M.A. Condutância estomática, transpiração e fotossíntese em laranjeira 'Valência' submetida ao estresse hídrico. Revista Brasileira de Fisiologia Vegetal, Londrina, v.11, p.29-34, 1999.

NUNES, W.M.; MEDINA, C.L.; MACHADO, M.A.; MACHADO, E.C.; MULLER, G.W.; CORAZAA-NUNES, M.J. Transmissão de Xylella fastidiosa para mudas de citros através da encostia de plantas-inóculo. Laranja, Cordeirópolis, v.25, p.349-356, 2004.

POOLER, M.R.; HARTUNG, J.S. Specific PCR detection and identification of Xylella fastidiosa strains causing citrus variegated chlorosis. Current Microbiology, New York, v.31, p.377-381, 1995.

PURCELL, A.H.; HOPKINS, D.L. Fastidious xylem-limited bacterial plant pathogens. Annual Review of Phytopathology, Boca Raton, v.34, p.131-151, 1996.

RIBEIRO, R.V. Variação sazonal da fotossíntese e relações hídricas em laranjeira 'Valência'. 2006.157p. Tese (Doutorado) - Escola Superior de Agricultura "Luiz de Queiroz", Universidade de São Paulo, Piracicaba, 2006.

RIBEIRO, R.V.; MACHADO, E.C., OLIVEIRA, R.F. Growthand leaf-temperature effects on photosynthesis of sweet orange seedlings infected with Xylella fastidiosa. Plant Pathology, London, v.53, p.334-340, 2004.

RIBEIRO, R.V; MACHADO, E.C.; OLIVEIRA, R.F. Early photosynthetic responses of sweet orange plants infected with Xylella fastidiosa. Physiological and Molecular Plant Pathology, London, v.62, p.167-173, 2003a.

RIBEIRO, R.V; MACHADO, E.C.; BRUNINI, O. Ocorrência de condições ambientais para a indução do florescimento em laranjeiras no Estado de São Paulo. Revista Brasileira de Fruticultura, Jaboticabal, v.28, p. 247-253, 2006.

RIBEIRO, R.V.; MACHADO, E.C.; OLIVEIRA, R.F.; PIMENTEL, C. High temperature effects on the response of photosynthesis to light in sweet orange plants infected with Xylella fastidiosa. Brazilian Journal of Plant Physiology, Londrina, v.15, p.8997, 2003b.

ROLIM, G.S.; SENTELHAS, P.C.; BARBIERI,V. Planilhas no ambiente Execel ${ }^{\mathrm{TM}}$ para cálculos de balanços hídricos: normal, seqüencial, de cultura e de produtividade real e potencial. Revista Brasileira de Agrometeorologia, Santa Maria, v. 6, n. 1, p. 133-137, 1998. 